\title{
Adjunctive Memantine Therapy for Cognitive Impairment in Chronic Schizophrenia: A Placebo-Controlled Pilot Study
}

\author{
Jung Goo Lee', Sae Woom Lee ${ }^{2}$, Bong Ju Lee ${ }^{3}$, Sung Woo Park', \\ Gyung Mee $\mathrm{Kim}^{3}$ and Young Hoon $\mathrm{Kim}^{5}$ \\ 1'Department of Psychiatry, Haeundae Paik Hospital, College of Medicine and Paik Institute for Clinical Research, Inje University, Busan, Korea \\ ${ }^{2}$ Department of Psychiatry, Jamyung Hospital, Busan, Korea \\ ${ }^{3}$ Department of Psychiatry, Haeundae Paik Hospital, College of Medicine, Inje University, Busan, Korea \\ ${ }^{4}$ Department of Neuroscience Research, Paik Institute for Clinical Research, Inje University, Busan, Korea \\ ${ }^{5}$ Department of Psychiatry, Haeundae Paik Hospital, School of Medicine and Paik Institute for Clinical Research, \\ FIRST Research Group, Inje University, Busan, Korea
}

Objective To investigate the effects of memantine, an N-methyl-d-aspartate (NMDA) receptor antagonist, on cognitive impairments in patients with chronic schizophrenia.

Methods A 12-week, placebo-controlled trial was conducted to determine the effectiveness of memantine as an adjunctive treatment with conventional antipsychotic medications in 26 patients with chronic schizophrenia. The subjects were evaluated with the Korean version of the Mini-Mental State Examination (K-MMSE), the Positive and Negative Syndrome Scale (PANSS), the Hamilton Rating Scale for Depression (HAM-D), and a standard neuropsychological screening test.

Results Memantine treatment was not associated with significantly improved cognitive test scores compared with the placebo control treatment. An improvement in the scores on the PANSS negative subscale was noted with memantine, but it was not significant.

Conclusion Adjunctive memantine treatment did not improve cognitive functioning or affect psychopathology in patients with chronic schizophrenia in the present study. Memantine, however, was tolerated well and did not exacerbate positive symptoms in patients with chronic schizophrenia.

Psychiatry Investig 2012;9:166-173

Key Words Memantine, Cognition, Antipsychotic drugs, Schizophrenia, Tolerability.

\section{INTRODUCTION}

Cognitive impairment represents a core feature of schizophrenia in the majority of patients with the disorder. ${ }^{1,2}$ Cognitive deficits appear during the initial episode of the illness ${ }^{3}$ and may appear even in those who are not taking antipsychotic medications, ${ }^{4,5}$ suggesting that these deficits do not reflect the deteriorative effects of treatment. Cognitive impairment is associated with poor functional outcome and longterm prognosis. ${ }^{6}$ Because cognitive impairment is among the

Received: March 24, 2011 Revised: December 25, 2011

Accepted: February 24, 2012 Available online: May 22, 2012

$\triangle$ Correspondence: Young Hoon Kim MD, PhD

Department of Psychiatry, Haeundae Paik Hospital, School of Medicine and Paik Institute for Clinical Research, FIRST Research Group, Inje University, 1435 Jwa-dong, Haeundae-gu, Busan 612-862, Korea

Tel: +82-51-797-3303, Fax: +82-51-894-6709, E-mail: npkyh@chol.com

(a) This is an Open Access article distributed under the terms of the Creative Commons Attribution Non-Commercial License (http://creativecommons.org/licenses/bync/3.0) which permits unrestricted non-commercial use, distribution, and reproduction in any medium, provided the original work is properly cited. strongest predictors of functional outcome in patients with schizophrenia ${ }^{6,7}$ the improvement of cognitive functioning has been identified as an important goal of treatment. ${ }^{8,9}$

Despite the known beneficial effects of conventional antipsychotics on positive symptoms, some studies have shown that these drugs might have negative effects on cognitive functioning, ${ }^{10,11}$ although other, more systematic analyses have suggested that such drugs provide a modest benefit. ${ }^{12}$ However, evidence also exists that atypical antipsychotic drugs might benefit cognitive functioning. Atypical antipsychotic drugs have been associated with greater improvement in cognitive functioning than conventional antipsychotic medications, ${ }^{13-15}$ although these benefits were relatively slight and have not been consistently shown. Thus, although atypical antipsychotic drugs may offer some benefits to cognitive functioning in schizophrenia, ${ }^{17}$ significant deficits still persist in this domain and alternative therapies for enhancing cognitive functioning are required. 
Several novel strategies to treat cognitive impairment in schizophrenia have been explored. Extensive psychopharmacological research has focused on dopamine receptors in the prefrontal cortex, nicotinic and muscarinic acetylcholine receptors, the glutamatergic excitatory synapse, various serotonin receptors, and the $\gamma$-aminobutyric acid (GABA) system. ${ }^{18}$ Previously, Lee and colleagues ${ }^{19}$ conducted a placebocontrolled trial of galantamine, a combined acetylcholinesterase inhibitor and allosteric potentiator of the nicotinic receptor, to examine the effects of the drug on the cognitive functioning of individuals with chronic schizophrenia. This trial showed no significant effects on cognitive functioning.

Glutamate is the primary excitatory neurotransmitter for approximately $60 \%$ of neurons ${ }^{20}$ and also plays a principal role in modulating long-term potentiation. Moreover, glutamate is considered to be a key cellular mechanism in learning and memory. ${ }^{21}$ Glutamate dysregulation may be involved in the neuropathology of schizophrenia, ${ }^{22}$ as evidenced by studies using $\mathrm{N}$-methyl-D-aspartate (NMDA) receptor antagonists, phencyclidine (PCP) and ketamine. PCP and ketamine produce the wide range of schizophrenic symptoms, including psychotic symptoms, negative symptoms, and cognitive impairment. ${ }^{23,24}$ NMDA hypofunctioning results in decreased stimulation of central GABAergic neurons. ${ }^{25}$ This ultimately may lead to the excessive release of glutamate into the synapse and consequently causes significant neuronal cell death. ${ }^{26}$ Thus, NMDA-mediated neuronal cell death is believed to play a role in the pathology of schizophrenia. Therefore, drugs that block excessive NMDA receptor-induced glutamate activity may attenuate this excitotoxic process. ${ }^{27}$

Memantine is currently approved for the treatment of moderate to severe Alzheimer's disease. It is a moderate affinity, noncompetitive, voltage-dependent NMDA receptor antagonist with rapid kinetics. ${ }^{26}$ These pharmacological features might allow memantine to modulate the pathological NMDA receptor activity thought to occur in Alzheimer's disease, while permitting normal physiological activation of the receptor required for learning and memory. ${ }^{29,30}$ Memantine is clinically well tolerated and lacks the psychotomimetic effects seen with other NMDA receptor antagonists such as ketamine and PCP. ${ }^{28,31}$ Because memantine treatment successfully slows neurodegeneration in dementia, ${ }^{32}$ it may also have a positive impact on the symptoms of schizophrenia. ${ }^{33}$ Krivoy and colleagues ${ }^{34}$ reported that menantine, in combination with conventional antipsychotic treatment, improved the negative symptoms of schizophrenia. Moreover, de Luceana and colleague ${ }^{35}$ reported that memantine in combination with clozapine therapy was associated with improvement in negative and positive symptoms. Lieberman and colleagues, ${ }^{36}$ however, reported that memantine was not efficacious as an adjunctive therapy.
In this randomized, double blind, placebo-controlled study, the potential effects of adjunctive memantine treatment on cognitive functioning in chronic schizophrenia was investigated. In addition, patient psychopathology was evaluated, and the adverse effects of memantine were assessed.

\section{METHODS}

\section{Subjects}

Subjects aged between 18 and 50 years were recruited from seven in-patient units in hospitals located in Busan and Masan, South Korea. The hospitals included Jamyung, Semyoung, Dongnae, Daenam, Busan Municipal, Hyungju, and Dongsuh. Informed consent was obtained from each patient, and the Institutional Review Board at Busan Paik Hospital approved the protocol for the present study (Trial Number: 07-27). All patients were diagnosed with schizophrenia according to the standard structured clinical interview for DSM-IV Axis I disorders (SCID-I) ${ }^{37}$ and had been stabilized using conventional antipsychotic medications for a minimum of three months prior to this study. The level of cognitive impairment required for participation was defined as a total performance score between 18 and 24 on the Korean version of the Mini-Mental Status Examination. ${ }^{38,39}$ Subjects with a history of substance abuse or dependence, head trauma, severe neurological disorders, depression, or other medical problems were excluded. Although patients who were undergoing treatment with medications that affected cognitive performance were also excluded, patients receiving antiparkinsonian anticholinergic or benzodiazepine-based drugs were included if the dosing regimen did not change over the 12-week study period. Smokers were also included in this study.

\section{Study design}

Twenty-six subjects were enrolled in the 12-week, double blind trial. Simple randomization based on a random-numbers table was used to assign subjects to either the placebo or the memantine group. Central randomization was also used to avoid the center effect. An investigator who was unaware of randomization assignments was assigned to each site to guarantee the integrity of the double-blind study design. After the baseline evaluation, subjects were randomly selected to receive memantine treatment or a placebo, in addition to a fixed daily dose of conventional antipsychotic medication (chlorpromazine-equivalent dose: $1145 \mathrm{mg} /$ day). ${ }^{40}$ Subjects in the memantine group received an initial dose of five $\mathrm{mg} /$ day, which was increased weekly in five mg increments until reaching a maximum dose of $20 \mathrm{mg} /$ day. This maximum dose was chosen according to the effective dose established for patients with dementia. ${ }^{41}$ Primary (neuropsychological tests), 
and secondary outcome (psychiatric symptoms) variables were assessed at baseline, week 6 , and week 12 . The checklist for adverse events was completed at weeks 6 and 12 .

\section{Assessment}

The Positive and Negative Symptom Scale ${ }^{42}$ and the 17item Hamilton Rating Scale for Depression ${ }^{43}$ were used to assess the severity of psychiatric symptoms and depressed mood. The Clinical Global Impression Severity and Improvement scales (CGI-S and CGI-I) were also administered to all subjects. Adverse events in response to memantine treatment were assessed using an adverse events checklist, which included the adverse events mostly commonly observed in patients with dementia. ${ }^{44} \mathrm{~A}$ battery of neuropsychological tests was administered to evaluate changes in several domains of cognitive functioning. The K-MMSE, the Hopkins Verbal Learning Test (HVLT), the Rey Complex Figure Test (RCFT), the Digit Span Forward and Backward Test, the Digit Symbol Substitution Test (DSST), the Stroop test, the Trail Making Test (Part A), the Verbal Fluency Test (VFT), and the Boston Naming Test were used to assess attention, auditory and visual memory, and executive functioning. The HVLT was also used to examine immediate memory span, new learning, susceptibility to interference, and delayed recall. The VFT was used to examine verbal productivity and intactness of the lexical system.

\section{Analyses}

Baseline comparisons between the two groups were per- formed using the Mann-Whitney $\mathrm{U}$ test for continuous variables and Fisher's exact test for categorical variables. The efficacy of memantine and placebo were analyzed with repeated measures analysis of variance (ANOVA) using group (memantine versus placebo) as the between-subjects factor and time (baseline, week 6 , and week 12) as the within-subjects factor. A $p$ value of $\leq 0.05$ was considered statistically significant.

\section{RESULTS}

\section{Demographic data}

Twenty-nine subjects met the eligibility criteria at baseline. However, three subjects withdrew their consent after random assignment. The remaining 26 subjects were randomly assigned to memantine $(n=15)$ or placebo $(n=11)$ treatment groups and completed the 12-week trial.

Table 1 presents demographic and baseline data for the study population. No significant differences in demographic or clinical variables were observed between the treatment groups at baseline. The following mean scores \pm standard deviation (SD) were recorded for the memantine versus placebo groups, respectively: PANSS: $74.5 \pm 14.9,74.7 \pm 14.2$; HAM-D: $1.4 \pm 2.0,2.2 \pm 1.8$; and K-MMSE: $22.0 \pm 1.6,21.6 \pm 1.6$. All subjects also received conventional antipsychotic drugs, and the mean chlorpromazine-equivalent dose did not differ between treatment groups. Fourteen patients $(53.8 \%)$ received a combination of two antipsychotic drugs.

Table 1. Demographic and baseline clinical data

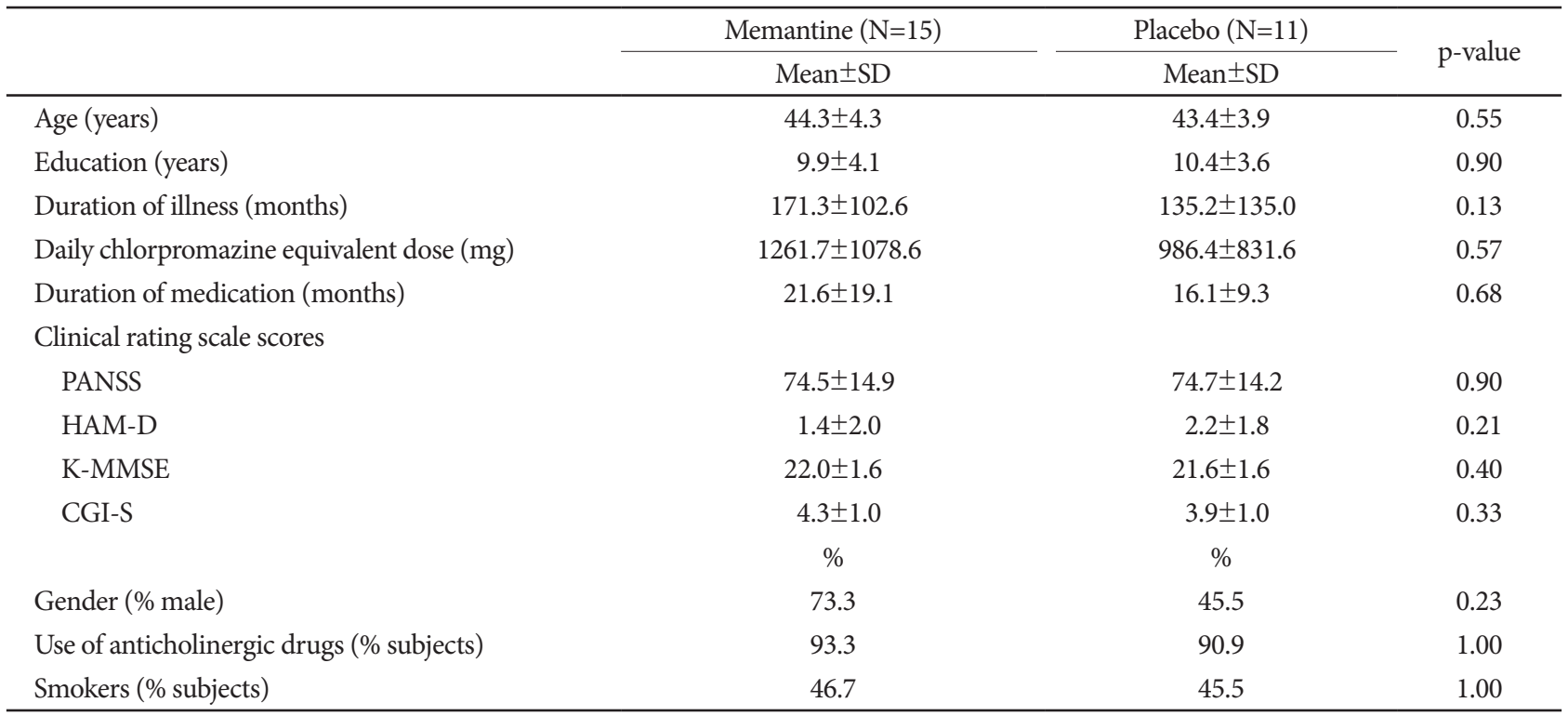

Data were analyzed using the Mann-Whitney U-test for continuous variables and Fisher's exact test for categorical variables. SD: standard deviation, PANSS: Positive and Negative Syndrome Scale, HAM-D: Hamilton Rating Scale for Depression, K-MMSE: Korean version of the Mini-Mental State Examination, CGI-S: Clinical Global Impression Ratings-Severity 


\section{Effect of adjunctive memantine therapy on psychiatric symptoms}

Psychiatric symptoms at baseline and week 12 did not change in response to memantine treatment. Mean PANSS scores did not differ between the memantine and placebo groups (Table 2). None of the subjects displayed a favorable response to memantine treatment in terms of their CGI-S or CGI-I scores (i.e., an improvement of $\geq 2$ points).

\section{Effect of adjunctive memantine therapy \\ on K-MMSE scores}

The mean K-MMSE score increased from $22.0 \pm 1$.6 at base-

Table 2. Effects of memantine compared with placebo on psychiatric assessment scores over the 12-week study period

\begin{tabular}{|c|c|c|c|c|c|}
\hline & \multirow{2}{*}{\multicolumn{2}{|c|}{$\begin{array}{c}\text { Memantine }(\mathrm{N}=15) \\
\text { Mean } \pm \mathrm{SD}\end{array}$}} & \multirow{2}{*}{\multicolumn{2}{|c|}{$\begin{array}{c}\text { Placebo }(\mathrm{N}=11) \\
\text { Mean } \pm \mathrm{SD}\end{array}$}} & \multirow{3}{*}{ p-value } \\
\hline & & & & & \\
\hline & Baseline & Week 12 & Baseline & Week 12 & \\
\hline \multicolumn{6}{|l|}{ PANSS } \\
\hline Total & $74.5 \pm 14.9$ & $73.6 \pm 17.5$ & $74.7 \pm 14.2$ & $74.3 \pm 14.6$ & 0.93 \\
\hline Positive subscale & $17.3 \pm 6.9$ & $17.9 \pm 7.2$ & $18.7 \pm 4.9$ & $17.4 \pm 4.8$ & 0.33 \\
\hline Negative subscale & $21.3 \pm 5.0$ & $20.5 \pm 5.1$ & $19.8 \pm 6.5$ & $20.7 \pm 6.5$ & 0.12 \\
\hline General psychopathology subscale & $35.1 \pm 8.4$ & $35.3 \pm 9.1$ & $36.2 \pm 7.2$ & $36.2 \pm 7.7$ & 0.89 \\
\hline HAM-D & $1.4 \pm 2.0$ & $0.9 \pm 1.3$ & $2.2 \pm 1.8$ & $1.6 \pm 1.7$ & 0.99 \\
\hline CGI-S & $4.3 \pm 1.0$ & $4.3 \pm 1.0$ & $3.9 \pm 1.0$ & $3.7 \pm 1.3$ & 0.82 \\
\hline
\end{tabular}

Data were analyzed using repeated measures analysis of variance (ANOVA). p-value was calculated from time by group interaction. SD: standard deviation, PANSS: Positive and Negative Syndrome Scale, HAM-D: Hamilton Rating Scale for Depression, CGI-S: Clinical Global Impression Ratings-Severity

Table 3. Effects of memantine compared with placebo on measures of cognitive functioning over the 12-week study period

\begin{tabular}{|c|c|c|c|c|c|}
\hline & \multicolumn{2}{|c|}{ Memantine $(\mathrm{N}=15)$} & \multicolumn{2}{|c|}{ Placebo $(\mathrm{N}=11)$} & \multirow{3}{*}{ p-value } \\
\hline & \multicolumn{2}{|c|}{ Mean \pm SD } & \multicolumn{2}{|c|}{ Mean \pm SD } & \\
\hline & Baseline & Week 12 & Baseline & Week 12 & \\
\hline K-MMSE* & $22.0 \pm 1.6$ & $24.3 \pm 2.8$ & $21.6 \pm 1.6$ & $22.7 \pm 3.2$ & 0.41 \\
\hline \multicolumn{6}{|l|}{ HVLT $^{\dagger}$} \\
\hline Immediate recall & $13.0 \pm 5.5$ & $17.5 \pm 8.0$ & $12.6 \pm 5.2$ & $17.0 \pm 5.8$ & 0.24 \\
\hline Delayed recall & $4.1 \pm 2.7$ & $5.4 \pm 4.0$ & $3.8 \pm 2.8$ & $5.0 \pm 2.9$ & 0.89 \\
\hline Recognition & $7.3 \pm 3.2$ & $7.5 \pm 3.7$ & $5.9 \pm 3.0$ & $7.0 \pm 2.6$ & 0.70 \\
\hline \multicolumn{6}{|l|}{ RCFT* $^{*}$} \\
\hline Immediate recall & $17.4 \pm 4.5$ & $18.1 \pm 5.5$ & $16.4 \pm 8.7$ & $17.4 \pm 6.9$ & 0.55 \\
\hline Delayed recall & $2.5 \pm 2.0$ & $4.1 \pm 4.0$ & $1.2 \pm 1.0$ & $2.9 \pm 2.8$ & 0.28 \\
\hline Recognition & $5.7 \pm 1.9$ & $5.7 \pm 2.2$ & $5.2 \pm 2.6$ & $5.5 \pm 1.8$ & 0.88 \\
\hline \multicolumn{6}{|l|}{ Digit Span ${ }^{\dagger}$} \\
\hline Forward & $4.7 \pm 1.1$ & $4.7 \pm 1.1$ & $5.1 \pm 0.9$ & $5.6 \pm 1.2$ & 0.45 \\
\hline Backward & $2.9 \pm 1.0$ & $2.9 \pm 1.0$ & $3.0 \pm 1.0$ & $3.2 \pm 0.8$ & 0.20 \\
\hline DSST $^{\dagger}$ & $23.5 \pm 9.6$ & $29.5 \pm 10.2$ & $19.8 \pm 9.0$ & $23.4 \pm 7.8$ & 0.06 \\
\hline \multicolumn{6}{|l|}{ Stroop test ${ }^{\dagger}$} \\
\hline Letter & $111.8 \pm 0.6$ & $106.5 \pm 13.2$ & $110.0 \pm 3.9$ & $110.0 \pm 6.0$ & 0.26 \\
\hline Color & $48.2 \pm 20.6$ & $66.5 \pm 48.5$ & $47.7 \pm 22.6$ & $52.9 \pm 25.3$ & 0.59 \\
\hline Trail making part $\mathrm{A}^{\ddagger}$ & $99.6 \pm 79.0$ & $78.0 \pm 43.2$ & $130.3 \pm 105.5$ & $118.1 \pm 92.7$ & 0.65 \\
\hline Verbal fluency ${ }^{\dagger}$ & $11.8 \pm 3.8$ & $13.5 \pm 3.4$ & $10.6 \pm 3.5$ & $12.2 \pm 4.8$ & 0.49 \\
\hline Boston Naming Test ${ }^{\dagger}$ & $37.3 \pm 11.1$ & $41.0 \pm 11.8$ & $40.0 \pm 8.6$ & $43.5 \pm 9.4$ & 0.71 \\
\hline
\end{tabular}

Data were analyzed using repeated-measures analysis of variance (ANOVA). p-value was calculated from time by group interaction. *Scores, ${ }^{\dagger}$ Numbsers, `Seconds. K-MMSE: Korean Mini Mental State Examination, SD: standard deviation, HVLT: Hopkin’s Verbal Learning Test, RCFT: Rey Complex Figure Test, DSST: Digit Symbol Substitution Test 
Table 4. Adverse effects of memantine and placebo

\begin{tabular}{lcc}
\hline & Memantine $(\mathrm{N}=15)$ & Placebo $(\mathrm{N}=11)$ \\
\hline Dizziness & $3(20 \%)$ & $2(18 \%)$ \\
Diarrhea & $2(13 \%)$ & $2(18 \%)$ \\
Constipation & $2(13 \%)$ & $1(9 \%)$ \\
Headache & 0 & $1(9 \%)$ \\
Total & $7(47 \%)$ & $6(55 \%)$ \\
\hline
\end{tabular}

line to $24.3 \pm 2.8$ at week 12 in the memantine group and from $21.6 \pm 1.6$ at baseline to $22.7 \pm 3.2$ at week 12 in the placebo group. However, these increases were not significantly different at the end of study period $(\mathrm{p}=0.41)$.

\section{Effects of adjunctive memantine therapy on impaired cognitive functioning}

Table 3 summarizes the results of the tests of cognitive functioning for both groups. No statistically significant difference was observed between groups in regard to any cognitive measure, although several tests indicated slight improvements after memantine treatment. In addition, the mean scores for immediate and delayed recall on the HVLT increased in the memantine group compared to the placebo group, but overall scores did not differ between groups at the end of the study period. The mean value obtained on the Stroop test was larger in the memantine group, but differences between groups did not reach statistical significance. The mean score on the Trail Making Test decreased in the memantine group compared to the placebo group, but the overall scores of the groups did not differ at the end of the study period. Improved scores on the Boston Naming Test were observed in the memantine group, but the between-group difference was not significant. The treatment groups did not differ in regard to any other outcome measures, including the RCFT, the Digit Span Forward and Backward Test, and the VFT.

\section{Adverse events as a result of adjunctive memantine therapy}

Memantine was well tolerated and the incidence of adverse events was similar between groups. In total, $47 \%$ of the memantine group and $55 \%$ of the placebo group experienced adverse events. The most common adverse events were dizziness, diarrhea, and constipation, but these symptoms were transient and mild to moderate in intensity. No subject demonstrated serious adverse effects during the study (Table 4).

\section{DISCUSSION}

The present study investigated the effects of adjunctive memantine therapy in combination with conventional antipsychotic medication in patients with chronic schizophrenia. The cognitive functioning profiles of subjects in the present study were very similar to the profiles of subjects with dementia reported in previous studies. ${ }^{45,46}$ No statistically significant differences were observed in the memantine group compared with the placebo group. Therefore, these results do not support the hypothesis that adjunctive memantine therapy improves cognitive functioning. Similarly, adjunctive memantine therapy was not associated with improvements in the psychopathology of schizophrenia. Krivoy and colleagues ${ }^{34}$ reported that memantine did not improve cognitive functioning during a 6-week open-label study. Lieberman and colleagues also reported that memantine adjunctive therapy failed to affect cognitive symptoms. ${ }^{36}$ In this 8-week randomized, placebo-controlled study, memantine was used in combination with antipsychotic medication. Memantine did not have an effect on the Brief Assessment of Cognition in Schizophrenia (BACS) or the PANSS negative score. However, de Luceana and colleagues ${ }^{35}$ reported significantly increased MMSE scores after 12 weeks of adjunctive memantine treatment in combination with clozapine therapy. Krivoy and colleagues $^{34}$ reported a $21 \%$ decrease in the PANSS negative subscale scores. Significant improvement on the negative subscales of the Brief Psychiatry Rating Scale (BPRS) was reported by de Luceana and colleagues. ${ }^{35}$ Silver and colleagues ${ }^{47}$ showed that amantadine, an antiviral agent with indirect dopaminergic agonist and NMDA antagonist action, was associated with improved visuomotor coordination compared to a placebo treatment. However, amantadine did not show beneficial effects on cognitive functioning. Gama and colleagues ${ }^{48}$ reported that adjunctive memantine therapy improved scores on the Brief Psychiatric Rating Scale (BPRS) among patients with schizophrenia. However, the observed decrease in PANSS scores was not significantly different between groups in the present study, Despite the absence of data regarding the effects of memantine on patients with schizophrenia, memantine, unlike other NMDA receptor antagonists, did not induce psychosis. These observations indicate that memantine may represent a safer alternative for patients with schizophrenia.

Previous studies have suggested that the glutamatergic system is involved in the pathophysiology and treatment of depression. ${ }^{49}$ For this reason, patients with depression were excluded from the present study. During the study period, no significant differences related to depression were observed.

Although a recent study reported that memantine adjunctive therapy was associated with adverse treatment effects, ${ }^{36}$ fewer adverse events were reported with memantine therapy in patients with chronic schizophrenia in the present study compared with patients with Alzheimer's dementia (AD). Reisberg and colleagues ${ }^{41}$ reported adverse events in $84 \%$ of 
memantine-treated $\mathrm{AD}$ patients and $87 \%$ of placebo-group patients. Agitation and urinary tract infections were the most common adverse events.

Tariot and colleagues ${ }^{50}$ reported that $78 \%$ of $\mathrm{AD}$ patients receiving memantine and $72 \%$ of those receiving placebo experienced adverse events. At least $5 \%$ of the memantine group, double the proportion found in the placebo group, experienced confusion and headaches. However, in the current study, no differences in adverse events were observed between the memantine and placebo groups. This discrepancy between schizophrenia and $\mathrm{AD}$ in the occurrence of adverse events might derive from differences in the physiological characteristics or ages of subjects.

This study has several limitations. First, most subjects were undergoing treatment with anticholinergic drugs during the study period. A large body of evidence from human and nonhuman animal studies has established that the cholinergic neurotransmitter system is important for attention, memory, and learning. ${ }^{51,52}$ Anticholinergic drugs impair cognitive and information processing both in normal populations ${ }^{53}$ and in individuals with schizophrenia. ${ }^{54}$ Moreover, several lines of evidence indicate that NMDA antagonists interact with cholinergic systems, ${ }^{55-57}$ although the interaction between cholinergic and glutamatergic systems is complex and poorly understood. Second, the majority of subjects in this study were chronic and institutionalized patients and might have been unresponsive to memantine treatment for this reason. Moreover, the relatively high doses of antipsychotic drugs may have resulted in memantine insensitivity. Third, subjects in this study were allowed to smoke. It is known that cigarette smoking may enhance cognitive functioning in smokers with schizophrenia. ${ }^{58}$ Furthermore, the study duration may have been insufficient. Although this study cannot exclude the possibility of a task-learning effect, memantine therapy tended to show a stronger positive effect on cognitive functioning as time passed. Memantine treatment has been shown to significantly improve cognitive functioning for up to 28 weeks ${ }^{41}$ among those with Alzheimer's dementia. Other studies on the effects of memantine on cognitive functioning report improvement for 24 weeks. ${ }^{59,60}$ Therefore, we can hypothesize that the 12-week duration of this study might be too short to warrant any conclusions. Finally, the small sample size may have masked significant effects. Although this study can be regarded as pilot study for a large-scale trial, the implications of the results might be restricted, and further study with a larger sample is needed.

Cognitive impairment represents a cardinal feature of schizophrenia and a strong predictor of poor vocational and social outcomes. The level of cognitive impairment is a better predictor of functional outcome than is the severity of posi- tive or negative symptoms. Therefore, an urgent need exists to develop therapies that target cognitive deficits. Our findings indicate that adjunctive memantine therapy does not have beneficial effects on cognitive functioning or psychopathology among patients with schizophrenia. However, future studies that address the limitations described above are required to examine more deeply the effects of memantine on cognitive impairment in schizophrenia.

\section{Acknowledgments}

This work was supported by Grant from Inje University, 2010.

\section{REFERENCES}

1. McGurk SR, Moriarty PJ, Harvey PD, Parrella M, White L, Davis KL. The longitudinal relationship of clinical symptoms, cognitive functioning, and adaptive life in geriatric schizophrenia. Schizophr Res 2000;42: 47-55.

2. Lewis R. Should cognitive deficit be diagnostic criterion for schizophrenia? J Psychiatry Neurosci 2004;29:102-113.

3. Hoff AL, Riordan H, O’Donnell DW, Morris L, DeLisi LE. Neuropsychological functioning of first-episode schizophreniform patients. Am J Psychiatry 1992;149:898-903.

4. Mohamed S, Paulsen JS, O'Leary D, Arndt S, Andreasen N. Generalized cognitive deficits in schizophrenia: a study of first-episode patients. Arch Gen Psychiatry 1999;56:749-754.

5. Hill SK, Schuepbach D, Herbener ES, Keshavan MS, Sweeney JA. Pretreatment and longitudinal studies of neuropsychological deficits in antipsychotic-naive patients with schizophrenia. Schizophr Res 2004;68: 49-63.

6. Green MF. What are the functional consequences of neurocognitive deficits in schizophrenia? Am J Psychiatry 1996;153:321-330.

7. Velligan DI, Bow-Thomas CC, Mahurin RK, Miller AL, Halgunseth LC. Do specific neurocognitive deficits predict specific domains of community function in schizophrenia? J Nerv Ment Dis 2000;188:518524.

8. Davidson M, Keefe RS. Cognitive impairment as a target for pharmacological treatment in schizophrenia. Schizophr Res 1995;17:123-129.

9. Harvey PD, Green MF, Keefe RS, Velligan DI. Cognitive functioning in schizophrenia: a consensus statement of its role in the definition and evaluation of effective treatments for the illness. J Clin Psychiatry 2004; 65:361-372.

10. Bilder RM, Turkel E, Lipschutz-Broch L, Lieberman JA. Antipsychotic medication effects on neuropsychological functions. Psychopharmacol Bull 1992;28:353-366.

11. Blyler CR, Gold JM. Cognitive Effects of Typical Antipsychotic Treatment: Another Look. In: Sharma T, Harvey P, Editors. Cognition in Schizophrenia: Impairments, Importance, and Treatment Strategies. New York: Oxford University Press, 2000, p. 252-271.

12. Mishara AL, Goldberg TE. A meta-analysis and critical review of the effects of conventional neuroleptic treatment on cognition in schizophrenia: opening a closed book. Biol Psychiatry 2004;55:1013-1022.

13. Purdon SE, Jones BD, Stip E, Labelle A, Addington D, David SR, et al. Neuropsychological change in early phase schizophrenia during 12 months of treatment with olanzapine, risperidone, or haloperidol. The Canadian Collaborative Group for research in schizophrenia. Arch Gen Psychiatry 2000;57:249-258.

14. Harvey PD, Keefe RS. Studies of cognitive change in patients with schizophrenia following novel antipsychotic treatment. Am J Psychiatry 2001;158:176-184.

15. Bilder RM, Goldman RS, Volavka J, Czobor P, Hoptman M, Sheitman $B$, et al. Neurocognitive effects of clozapine, olanzapine, risperidone, 
and haloperidol in patients with chronic schizophrenia or schizoaffective disorder. Am J Psychiatry 2002;159:1018-1028.

16. Keefe RS, Silva SG, Perkins DO, Lieberman JA. The effects of atypical antipsychotic drugs on neurocognitive impairment in schizophrenia: a review and meta-analysis. Schizophr Bull 1999;25:201-222.

17. Woodward ND, Purdon SE, Meltzer HY, Zald DH. A meta-analysis of neuropsychological change to clozapine, olanzapine, quetiapine, and risperidone in schizophrenia. Int J Neuropsychopharmacol 2005;8: 457-472.

18. Gray JA, Roth BL. Molecular targets for treating cognitive dysfunction in schizophrenia. Schizophr Bull 2007;33:1100-1119.

19. Lee SW, Lee JG, Lee BJ, Kim YH. A 12-week, double-blind, placebocontrolled trial of galantamine adjunctive treatment to conventional antipsychotics for the cognitive impairments in chronic schizophrenia. Int Clin Psychopharmacol 2007;22:63-68.

20. Nieuwenhuys R. The neocortex. An overview of its evolutionary development, structural organization and synaptology. Anat Embryol (Berl) 1994;190:307-337.

21. Malenka RC, Bear MF. LTP and LTD: an embarrassment of riches. Neuron 2004;44:5-21.

22. Tsapakis EM, Travis MJ. Glutamate and psychiatric disorders. Adv Psychiatr Treat 2002;8:189-197.

23. Javitt DC. Negative schizophrenic symptomatology and the PCP (phencyclidine) model of schizophrenia. Hillside J Clin Psychiatry 1987;9:12-35.

24. Olney JW, Newcomer JW, Farber NB. NMDA receptor hypofunction model of schizophrenia. J Psychiatr Res 1999;33:523-533.

25. Farber NB. The NMDA receptor hypofunction model of psychosis. Ann N Y Acad Sci 2003;1003:119-130.

26. Millan MJ. N-Methyl-D-aspartate receptors as a target for improved antipsychotic agents: novel insights and clinical perspectives. Psychopharmacology (Berl) 2005;179:30-53.

27. Ikonomidou C, Turski L. Why did NMDA receptor antagonists fail clinical trials for stroke and traumatic brain injury? Lancet Neurol 2002;1: 383-386.

28. Parsons CG, Danysz W, Quack G. Memantine is a clinically well tolerated N-methyl-D-aspartate (NMDA) receptor antagonist--a review of preclinical data. Neuropharmacology 1999;38:735-767.

29. Danysz W, Parsons CG, Mobius HJ, Stoffler E, Quack G. Neuroprotective and symptomatological action of memantine relevant for Alzheimer's disease--a unified glutamatergic hypothesis on the mechanism of action. Neurotox Res 2000;2:85-87.

30. Rogawski MA, Wenk GL. The neuropharmacological basis for the use of memantine in the treatment of Alzheimer's disease. CNS Drug Rev 2003;3:275-308.

31. Orgogozo JM, Rigaud AS, Stoffler A, Mobius HJ, Forette F. Efficacy and safety of memantine in patients with mild to moderate vascular dementia: a randomized, placebo-controlled trial (MMM 300). Stroke 2002;33:1834-1839.

32. Heim C, Sontag KH. Memantine prevents progressive functional neurode generation in rats. J Neural Transm Suppl 1995;46:117-130.

33. Rands GS. Memantine as a neuroprotective treatment in schizophrenia. Br J Psychiatry 2005;186:77.

34. Krivoy A, Weizman A, Laor L, Hellinger N, Zemishlany Z, Fischel T. Addition of memantine to antipsychotic treatment in schizophrenia inpatients with residual symptoms: a preliminary study. Eur Neuropsychopharmacol 2008;18:117-121.

35. de Lucena D, Fernandes BS, Berk M, Dodd S, Medeiros DW, Pedrini M, et al. Improvement of negative and positive symptoms in treatment-refractory schizophrenia: a double-blind, randomized, placebo-controlled trial with memantine as add-on therapy to clozapine. J Clin Psychiatry 2009;70:1416-1423.

36. Lieberman JA, Papadakis K, Csernansky J, Litman R, Volavka J, Jia XD, et al. A randomized, placebo-controlled study of memantine as adjunctive treatment in patients with schizophrenia. Neuropsychopharmacol- ogy 2009;34:1322-1329.

37. First MB, Spitzer RL, Gibbon M, Williams JB. Structured Clinical Interview for DSM-IV Axis I Disorders (SCID-I). Arlington: American Psychiatric Publishing Incorporated; 1997.

38. Korean Association of Geriatric Psychiatry. Korean Assessment Scales for Demented Patients. Seoul, Korea: Hakjisa; 2003.

39. Jeong SK, Cho KH, Kim JM. The usefulness of the Korean version of modified Mini-Mental State Examination (K-mMMSE) for dementia screening in community dwelling elderly people. BMC Public Health 2004;4:31.

40. Preskorn SH. Clinical application of the concept of relative potency: an example involving chlorpromazine and haloperidol. J Psychiatr Pract 2005;11:258-261.

41. Reisberg B, Doody R, Stoffler A, Schmitt F, Ferris S, Mobius HJ, et al. Memantine in moderate-to-severe Alzheimer's disease. N Engl J Med 2003;348:1333-1341.

42. Key SR, Opler LA, Lindenmayer JP. Reliability and validity of the positive and negative syndrome scale for schizophrenics. Psychiatry Res 1988;23:99-110.

43. Hamilton M. Development of a rating scale for primary depressive illness. Br J Soc Clin Psychol 1967;6:278-296.

44. H Lundbeck A/S. Memantine Hydrochloride (Ebixa): Summary of Product Characteristics. Copenhagen, Denmark: H Lundbeck A/S; 2002.

45. Hogervorst E, Combrinck M, Lapuerta P, Rue J, Swales K, Budge M. The Hopkins Verbal Learning Test and screening for dementia. Dement Geriatr Cogn Disord 2002;13:13-20.

46. Kuslansky G, Katz M, Verghese J, Hall CB, Lapuerta P, LaRuffa G, et al. Detecting dementia with the Hopkins Verbal Learning Test and the Mini-Mental State Examination. Arch Clin Neuropsychol 2004;19:89104.

47. Silver H, Goodman C, Isakov V, Knoll G, Modai I. A double-blind, cross-over comparison of the effects of amantadine or placebo on visuomotor and cognitive function in medicated schizophrenia patients. Int Clin Psychopharmacol 2005;20:319-326.

48. Gama CS, Antunes P, Moser C, Belmonte-de-Abreu PS. Memantine as an adjunctive therapy for schizophrenia negative symptoms. Rev Bras Psiquiatr 2005;27:257-258.

49. Zarate CA, Quiroz J, Payne J, Manji HK. Modulators of the glutamatergic system: implications for the development of improved therapeutics in mood disorders. Psychopharmacol Bull 2002;36:35-83.

50. Tariot PN, Farlow MR, Grossberg GT, Graham SM, McDonald S, Gergel I, et al. Memantine treatment in patients with moderate to severe Alzheimer disease already receiving donepezil: a randomized controlled trial. JAMA 2004;291:317-324.

51. Furey ML, Pietrini P, Haxby JV. Cholinergic enhancement and increased selectivity of perceptual processing during working memory. Science 2000;290:2315-2319.

52. Friedman JI. Cholinergic targets for cognitive enhancement in schizophrenia: focus on cholinesterase inhibitors and muscarinic agonists. Psychopharmacology (Berl) 2004;174:45-53.

53. Zachariah E, Kumari V, Galea A, Das M, Mehrotra R, Taylor D, et al. Effects of oral procyclidine administration on cognitive functions in healthy subjects: implications for schizophrenia. J Clin Psychopharmacol 2002;22:224-226.

54. Strauss ME, Reynolds KS, Jayaram G, Tune LE. Effects of anticholinergic medication on memory in schizophrenia. Schizophr Res 1990;3:127129.

55. Macro LA, Joshi RS, Brown C, Aldes LD, Chronister RB. Effects of cholinergic and anticholinergic drugs on ketamine-induced linguopharyngeal motor activity. Psychopharmacology (Berl) 1988;96:484-486.

56. Olney JW, Labruyere J, Wang G, Wozniak DF, Price MT, Sesma MA. NMDA antagonist neurotoxicity: mechanism and prevention. Science 1991;254:1515-1518.

57. Ikarashi Y, Yuzurihara M, Takahashi A, Ishimaru H, Shiobara T, Maru- 
yama Y. Direct regulation of acetylcholine release by N-methyl-D-aspartatic acid receptors in rat striatum. Brain Res 1998;795:215-220.

58. Sacco KA, Termine A, Seyal A, Dudas MM, Vessicchio JC, KrishnanSarin S, et al. Effects of cigarette smoking on spatial working memory and attentional deficits in schizophrenia: involvement of nicotinic receptor mechanisms. Arch Gen Psychiatry 2005;62:649-659.

59. Peskind ER, Potkin SG, Pomara N, Ott BR, Graham SM, Olin JT, et al.
Memantine treatment in mild to moderate Alzheimer's disease: A 24week randomized, controlled trial. Am J Geriatr Psychiatry 2006;14: 704-715.

60. Bakchins S, Loft $\mathrm{H}$. Memantine treatment in patients with mild to moderate Alzheimer's disease: results of a randomized, double-blind, placebo-controlled 6-month study. J Alzheimers Dis 2007;11:471-479. 